\title{
Cáncer colorrectal hereditario: análisis molecular de los genes APC y MLH 1
}

\author{
Felipe Bellolio $\mathbf{R}^{\mathbf{1}}$, Karin Álvarez $\mathbf{V}^{\mathbf{1}, 2 a}$, \\ Marjorie De la Fuente $L^{2 a}$, Francisca León $\mathbf{G}^{1}$, \\ Demian A Fullerton $M^{1}$, G onzalo Soto $D^{1}$, \\ Pilar Carvallo de SQ ${ }^{2 b}$, Francisco López-Köstner ${ }^{1}$. \\ Hereditary colorectal cancer: \\ Molecular analysis \\ of $A P C$ and MLH 1 genes
}

Background: Among colorectal cancer hereditary variants, two syndromes show a predisposition to the disease based on germline mutations: Familial Adenomatous Polyposis (FAP) and Hereditary Nonpolyposis Colorectal Cancer (HNPCC). Aim: To screen mutations in FAP and HNPCC families in Chile. Materials and Methods: Two FAP and one HNPCC families were studied. The APC gene (for FAP patients) and the MLH1 gene (for HNPCC patients), were screened for mutations on genomic DNA. The molecular analysis was performed through polymerase chain reaction, Single Strand Conformer Polymorphism (SSCP) and DNA sequencing. Mutations were defined as changes in the DNA sequence leading into a stop codon and a truncated protein. Results: In the two FAP families the analysis revealed a mutation consisting in the deletion of five nucleotides named c.3927 3931delAAAGA. The genetic study of the HNPCC family demonstrated the insertion of one adenine in codon 168 of exon 6, named c.504insA. Discussion: Germ-line mutations were identified in the three families. The relevance of these studies in a better knowledge of cancer susceptibility, and the possibility of identifying in relatives in risk by molecular diagnosis (Rev Méd Chile 2006; 134: 841-8).

(Key words: Adenomatous Polyposis Coli; Colorectal neoplasms; Colorectal neoplasms, Hereditary non polyposis; Germ-line mutation)

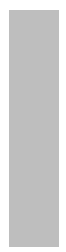

\footnotetext{
Recibido el 14 de septiembre, 2005. Aceptado el 27 de diciembre, 2005.

Financiado por proyecto FONDECYT \#1040827.

${ }^{1}$ Departamento de Cirugía Digestiva, Hospital Clínico, Facultad de Medicina. ${ }^{2}$ Departamento de Biología Celular y Molecular, Facultad de Ciencias Biológicas, Pontificia Universidad Católica de Chile. Santiago de Chile.

aBioquímica

bDoctora en Ciencias con mención en Biología
}

Correspondencia a: Dr. Francisco López-Köstner. Departamento de Cirugía Digestiva, Facultad de Medicina, Pontificia Universidad Católica de Chile. Marcoleta 367, Casilla 114-D, Santiago. Fono: 3543870. Fax: 6329620. E mail: flopez@med.puc.cl 
$\mathrm{E}^{1}$ cáncer colorrectal (CCR) es, actualmente, una causa importante de mortalidad, con más de mil muertes al año en nuestro país ${ }^{1}$. En países desarrollados con alta prevalencia de cáncer colomectal, se ha sugerido realizar un tamizaje a todo paciente mayor de 50 años, o antes a pacientes con mayor riesgo, con antecedentes familiares, enfermedades inflamatorias intestinales y otros ${ }^{2}$. En Chile, iniciativas como esta supondrían un alto costo, además que los estudios disponibles producen incomodidad en los pacientes.

Dentro de las variantes hereditarias de CCR se cuentan dos síndromes en los cuales la predisposición a la enfermedad se basa en una mutación de la línea germinal $^{3}$. Uno de ellos es la poliposis adenomatosa familiar $(\mathrm{PAF})^{4}$. Esta se caractenza por la presencia de múltiples adenomas colónicos (>100) de aparición temprana, y por ser autosómica dominante con una penetrancia de $100 \% 5,6$. Además, la PAF se asocia a lesiones en otros parénquimas, como adenomas periampulares, tumores desmoides, alteraciones retinales y cáncer papilar de tiroides, entre otras ${ }^{7-13}$.

En 1991, se identificó al gen supresor de tumores APC (cromosoma 5) y se determinó qué mutaciones en este gen son la causa principal de la $\mathrm{PAF}^{14}$. Este gen contiene 15 exones, entre los cuales, el de mayor tamaño es el exón 15 con 6570 pb. El gen APC codifica para la proteína APC, que se une a ßcatenina, promoviendo la degradación de esta última, regulando así su función. La ausencia de APC permite la entrada de ß-catenina al núcleo, la cual activa la expresión de genes que estimulan la proliferación celular. De esta forma, mutaciones que suprimen la función de APC, podrían ser responsables del inicio de un proceso neoplásico al perderse el control del supresor APC sobre ß-catenina. Así, la aparición de pólipos adenomatosos en todo el tracto digestivo, en especial en el colon, con una edad promedio de aparición a los 16 años, y de desarmollo del cáncer a los 39 años $^{6}$, pueden explicarse por un descontrol del ciclo celular iniciado por la ausencia de la función de APC.

Por otra parte, se estima que entre 1 y $5 \%$ de los cánceres colorrectales aparecen en pacientes portadores de cáncer de colon hereditario no poliposo (HNPCC) ${ }^{4,6,15}$. Este síndrome, fue descrito por Henry Lynch ${ }^{16}$ en 1966, en dos familias que presentaban cáncer colorrectal en ausencia de pólipos del colon, por lo cual también se le conoce como síndrome de Lynch.
Los individuos con HNPCC se caracterizan por presentar tumores a una edad temprana, de preferencia en el colon derecho y presentan antecedentes familiares de cáncer tanto de colon y recto, como de otros tejidos (endometrio, ovario, urotelio). Como característica importante, estos tumores presentan en su ADN genómico una inestabilidad microsatelital de alta frecuencia. Para la identificación de pacientes de riesgo se han elaborado criterios clínicos, entre los cuales se cuentan los criterios de Amsterdam I y II y Bethesda ${ }^{6}$.

Un alto porcentaje (90\%) de los pacientes HNPCC presentan mutaciones en la línea germinal, para el gen MLH1 (cromosoma 3, mRNA de 2524 pb, 19 exones) o bien para el gen MSH2 (cromosoma 2, mRNA 3145 pb, 16 exones) ${ }^{5}$. Estos dos genes codifican para enzimas que participan en el sistema de reparación del ADN. De esta forma, la ausencia de cualquiera de estas funciones celulares permite la acumulación de mutaciones en el $\mathrm{ADN}$, que al ocumir en genes supresores de tumores o protoncogenes, colaboran en el desarrollo del proceso neoplásico.

Recientemente, nuestro grupo publicó el análisis de genealogías y resultados quinúrgicos de pacientes HNPCC y PAF ${ }^{17,18}$. Es destacable la gran relevancia que ha cobrado la detección de mutaciones en los genes involucrados en cáncer de colon, especialmente en relación con el pronóstico y desarrollo del tumor, y en relación con el diagnóstico de familiares asintomáticos. En este trabajo presentamos el hallazgo de dos mutaciones, una en el gen APC y otra en el gen $\mathrm{MLH1}$, en tres familias chilenas.

\section{PACIENTES Y MÉTODOS}

Pacientes. Se incluyeron 5 pacientes: 2 con demostración histopatológica de cáncer y que cumplieran los criterios de Amsterdam para HNPCC (una familia) y 3 con diagnóstico histológico de PAF que demostrara la presencia de al menos 100 pólipos adenomatosos (2 familias).

Técnicas. Obtención de ADN genómico: el ADN genómico fue aislado a partir de $10 \mathrm{ml}$ de sangre periférica, mediante el protocolo descrito por Lahiri et al en $1991^{19}$. El ADN obtenido fue estudiado en busca de alteraciones del gen APC, en los pacientes con $\mathrm{PAF}$, o en el gen MLH1, en la familia con HNPCC.

Detección de mutaciones. El análisis molecular de los genes se realizó por la técnica de conformómeros de 
hebra simple (Single Strand Conformer Polymorphism-SSCP). Para esto se realizó la amplificación por PCR de todos los exones de los genes APC y MLH1 (menos el exón 15 del gen APC). Para el exón 15 del gen APC, se analizaron sólo aquellas regiones que presentan una alta frecuencia de mutaciones según está descrito en la literatura ${ }^{20}$. La reacción por PCR se llevó a cabo según el siguiente protocolo: en un volumen final de $50 \mu \mathrm{l}$ se agregan $100 \mathrm{ng}$ de ADN genómico, 25 pmoles de cada partidor, $1 \mathrm{U}$ de Taq ADN polimerasa (Fermentas), 0,2 $\mathrm{mM}$ de cada desoxinucleótido trifosfato (dATP,dCTP,dGTP y dTTP), $\mathrm{MgCl} 2$ 2,5 mM y amortiguador Taq (Tris-HCl $10 \mathrm{mM} \mathrm{pH}$ 8,8; KCl $50 \mathrm{mM}$, Nonidet P40 al 0,08\%). Los partidores utilizados para cada gen han sido previamente descritos en la literatura ${ }^{14,20-23}$. Los productos de PCR fueron desnaturados, colocándolos a $90^{\circ}$ por $5 \mathrm{~min}$ en una solución que contiene: formamida al 95\%, EDTA $20 \mu \mathrm{M}$, azul de bromofenol al 0,25\% p/v, xilencianol al 0,25\% p/v y NaOH 10 $\mathrm{mM}$. Posteriormente, estos productos se separan por electroforesis de alta resolución en geles de poliacrilamida $\mathrm{MDE}^{\mathrm{TM}}$ 0,5 X (Mutation Detection Enhancement, Cambrex Bio Science Rockland, Inc. ME, USA) en condiciones nativas. La electroforesis se realizó a una potencia constante de 3 watts por $14 \mathrm{~h}$ y el gel fue teñido con nitrato de plata.

Secuenciación de ADN. Los productos de PCR que presentan un cambio en la migración electroforética, con respecto a los controles en la técnica de SSCP, se someten a secuenciación en un secuenciador automático ABI PRISM 3100 v 3.7 (Applied Biosystems, CA, USA).

Se definieron como mutaciones las alteraciones genéticas que deriven en una proteína de menor tamaño, produciendo un efecto drástico sobre la función de la proteína, a través de la pérdida de dominios de interacción con otras moléculas o cambios conformacionales.

\section{RESULTADOS}

Análisis del gen APC en familias PAF. El caso índice de la familia PAF4, cuya genealogía se presenta en la Figura 1A, corresponde a un paciente de 26 años operado a los 21 años por PAF, sometido a colectomía total e íleo-recto

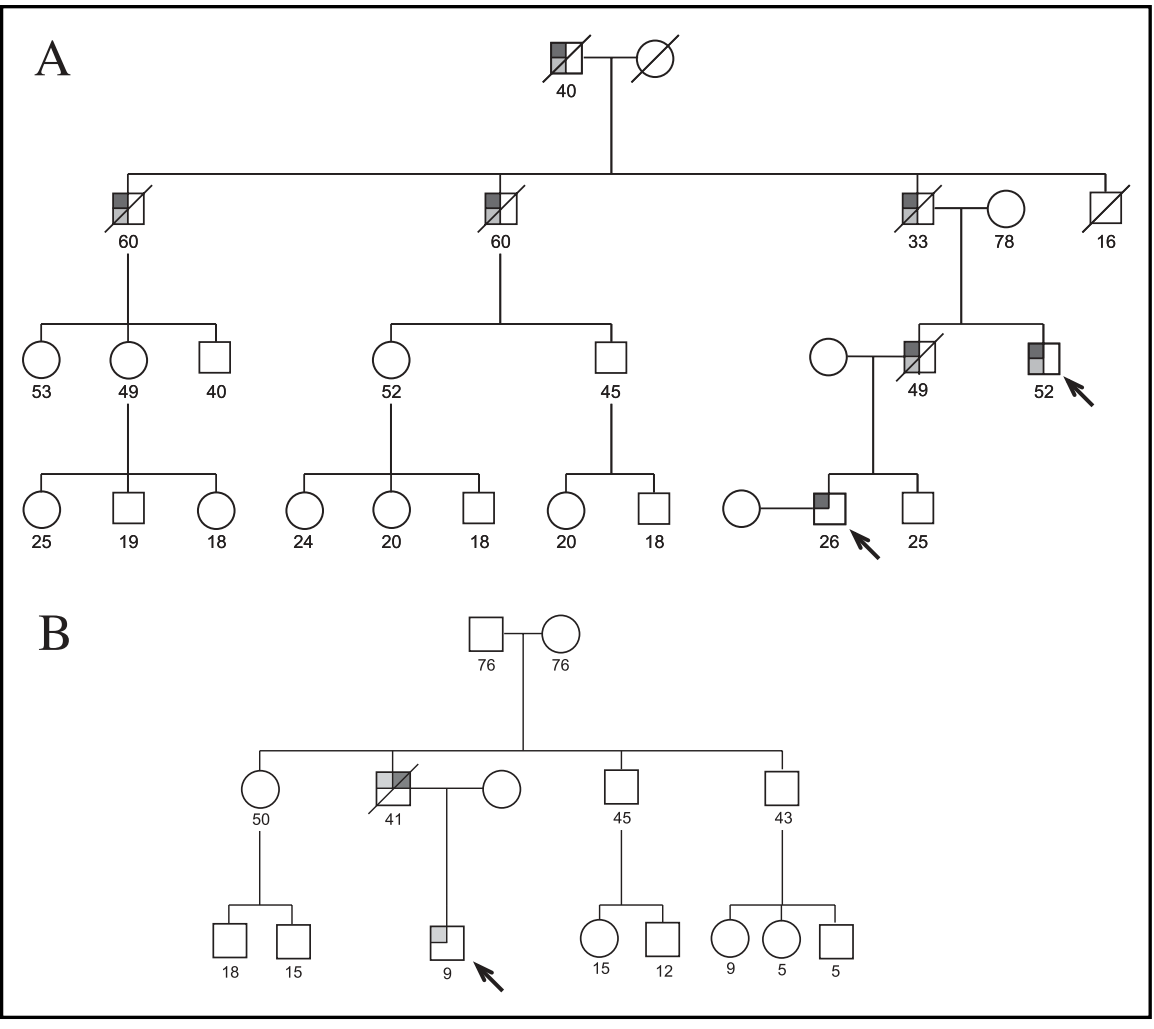

Figura 1. A: Genealogía de la familia PAF4. B: Genealogía de la familia PAF5. Las flechas indican los pacientes a los cuales se les realizó el estudio molecular. Bajo cada sujeto se indica la edad de fallecimiento o la edad actual.

$\bigcirc$ : mujer $\square$ : hombre $\varnothing$ : fallecido $\square$ : cáncer de colon $\square$ : PAF $\square$ : cáncer de páncreas. 
anastomosis. El hermano de su padre, actualmente de 52 años, fue sometido a una proctocolectomía total e ileostomía terminal por PAF a los 18 años, momento en que se diagnosticó un cáncer de colon sigmoides. Este familiar y el caso índice fueron sometidos al estudio genético molecular.

La familia PAF5 incluye a un paciente de 9 años, cuya genealogía se muestra en la Figura 1B. Su padre fue operado a los 22 años por PAF, y posteriormente falleció a los 41 años por cáncer de páncreas metastásico. Al paciente le fue diagnosticada una poliposis a los 6 años, posterior a lo cual presentó sangrado digestivo bajo intermitente. La endoscopia digestiva alta confirmó la presencia de pólipos adenomatosos en el estómago y el duodeno. Por presentar una poliposis sintomática, se decidió realizar una colectomía total más una íleo-recto anastomosis laparoscópica. El análi- sis molecular del gen APC se realizó sólo en este paciente.

En las dos familias mencionadas, el análisis molecular por medio de la técnica SSCP determinó cambios en la migración electroforética en un fragmento del exón 15 del gen APC (Figura 2A). La secuenciación de este fragmento reveló la deleción de cinco nucleótidos entre las posi-ciones 3927 y 3931 del cADN denominada c.3927 3931delAAAGA. Esta deleción provoca un desplazamiento del marco de lectura del mARN, derivando en la aparición de un codón de término prematuro. De esta forma, la traducción se interrumpe en el codón 1313, sintetizándose una proteína de tamaño menor a lo normal (2843 aminoácidos) (Figuras 2B y 2C).

Análisis del gen MLH1 en familia HNPCC. La genealogía de la familia HNPCC6 (Figura 3) está compues-

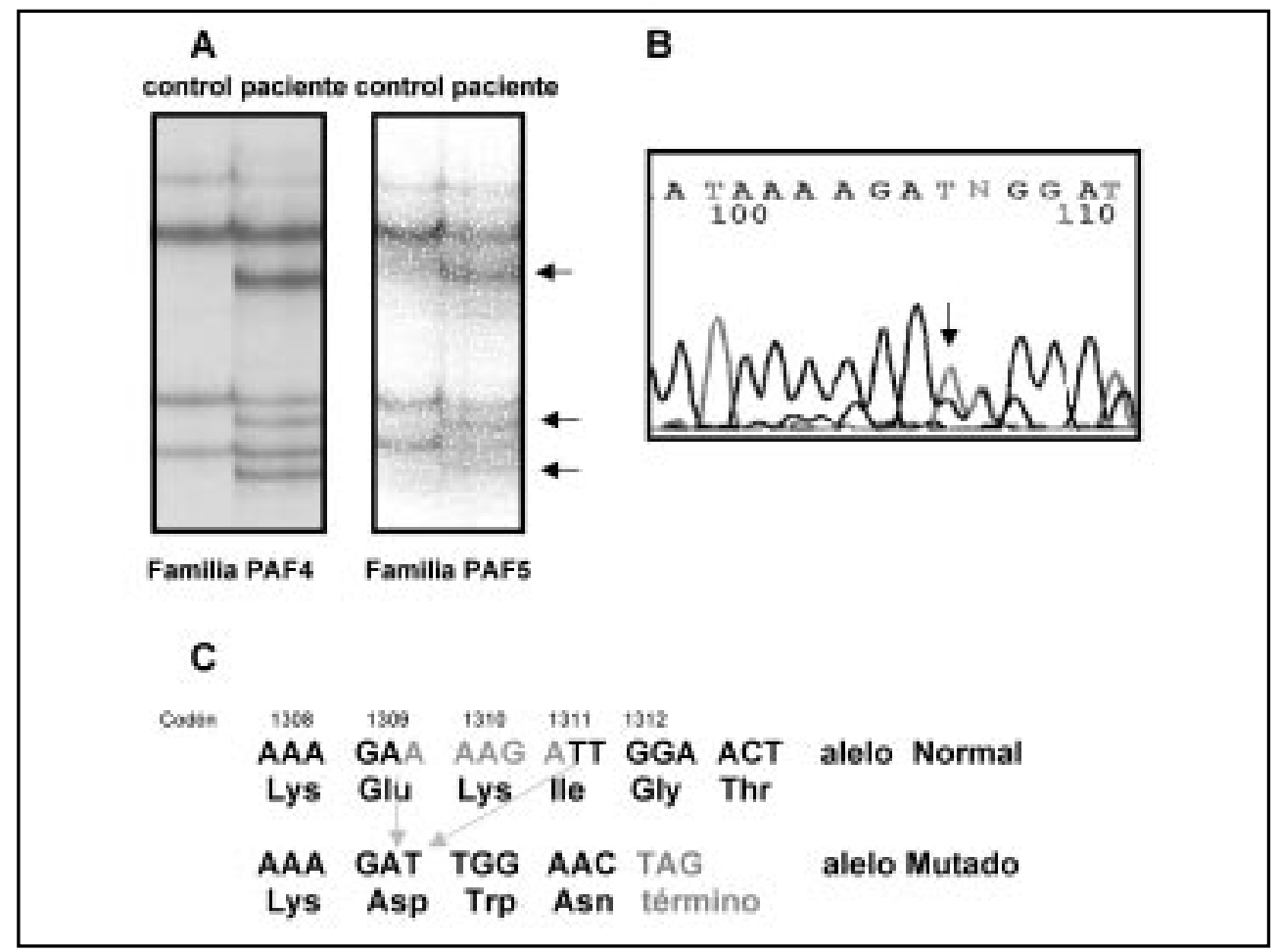

Figura 2. Análisis molecular del gen APC en las familias PAF4 y PAF5. A: análisis por SSCP de un fragmento del exón 15 del gen APC: se muestra una sección de la electroforesis en gel de MDE 0,5 X. Las flechas indican las bandas con migración electroforética diferente al control para ambos pacientes. B: Resultado de la secuencia de ADN: la flecha indica el inicio de secuencia alterada en uno de los alelos. C: Secuencias normal y mutada: se indica la lectura de las secuencias correspondientes a los dos alelos que presentan cada uno de los pacientes, indicando la deleción de 5 nucleótidos AAAGA. Bajo cada secuencia se indica el aminoácido correspondiente a cada codón, y sobre ésta la posición del codón en el mARN. 


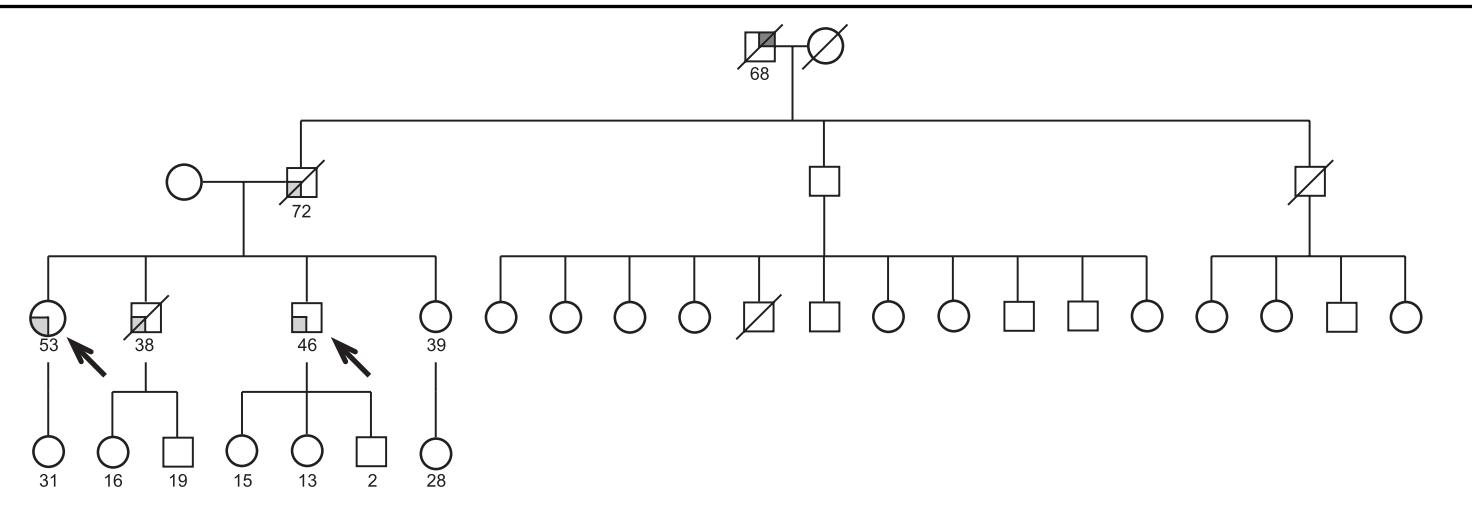

Figura 3. Genealogía de la familia HNPCC6. Las flechas indican los casos estudiados. Bajo cada sujeto se indica la edad de fallecimiento o la edad actual. $\bigcirc$ : mujer $\square$ : hombre $\varnothing$ : fallecido $\square$ : cáncer de colon $\square$ : cáncer de páncreas.

ta por una paciente de 53 años, operada de cáncer de colon derecho hace un año, realizándose una colectomía total más íleo-recto anastomosis. Su hermano fue operado anteriormente por cáncer de colon transverso a los 42 años, realizándose la misma cirugía. En estos dos pacientes se realizó un análisis molecular.

El estudio molecular del gen MLH1 mediante SSCP mostró una probable mutación en el exón 6 (Figura 4A). La secuenciación de este fragmento demostró una inserción de una adenina en el codón 168 del exón 6, denominada c.504insA. Esta inserción provoca un desplazamiento del marco de lectura del mARN derivando en la aparición de un codón de término prematuro. De esta forma, se obtiene una proteína trunca de 171 aminoácidos en comparación con la proteína normal de 756 aminoácidos (Figuras 4B y 4C).

\section{Discusión}

Dentro del espectro de los tumores colorrectales, aproximadamente 4 a $6 \%$ corresponde a dos entidades bien identificadas: PAF y HNPCC, para las cuales se ha identificado el gen de susceptibilidad correspondiente. En el primer caso, una mutación en el gen APC es la responsable de este cuadro, mientras que en el segundo, alteraciones en los genes MLH1 o MSH2 se encontrarían en la gran mayoría de los que presentan este síndrome.
Los familiares directos de los portadores de una mutación en estos genes presentan hasta 50\% de probabilidad de presentar el gen alterado. Por esta razón, todos deberían someterse a un estudio endoscópico precoz, ya que está demostrado que el identificar pacientes de riesgo permite detectar tumores en etapas tempranas, permitiendo una mejor sobrevida ${ }^{6,24-26}$. En los últimos diez años, el avance en el conocimiento de la genética molecular humana, ha permitido identificar los genes responsables de diversas enfermedades hereditarias, incluidos algunos tipos de cáncer. Esto mismo ha posibilitado identificar mutaciones causantes de estas patologías, permitiendo un diagnóstico preciso en aquellos pacientes portadores de la enfermedad, además de entregar a los no portadores la posibilidad de no someterse a estudios incómodos, de alto costo y de por vida.

En este estudio, el análisis de las dos familias PAF, mostró una deleción de 5 nucleótidos entre los codones 1308 y 1310 del exón 15, entre dos sitios de unión de ß-catenina. Esta mutación ha sido la más frecuentemente descrita en la literatura mundial en pacientes con PAF, y produce un codón de término con la síntesis de una proteína trunca. Esta proteína truncada carece de la segunda región de unión a ß-catenina, que es la de mayor importancia en la regulación negativa de ésta ${ }^{27}$. Es interesante que esta mutación ha sido asociada por diversos autores con una aparición más temprana de los pólipos $^{28-30}$, un mayor compromiso rectal con la 


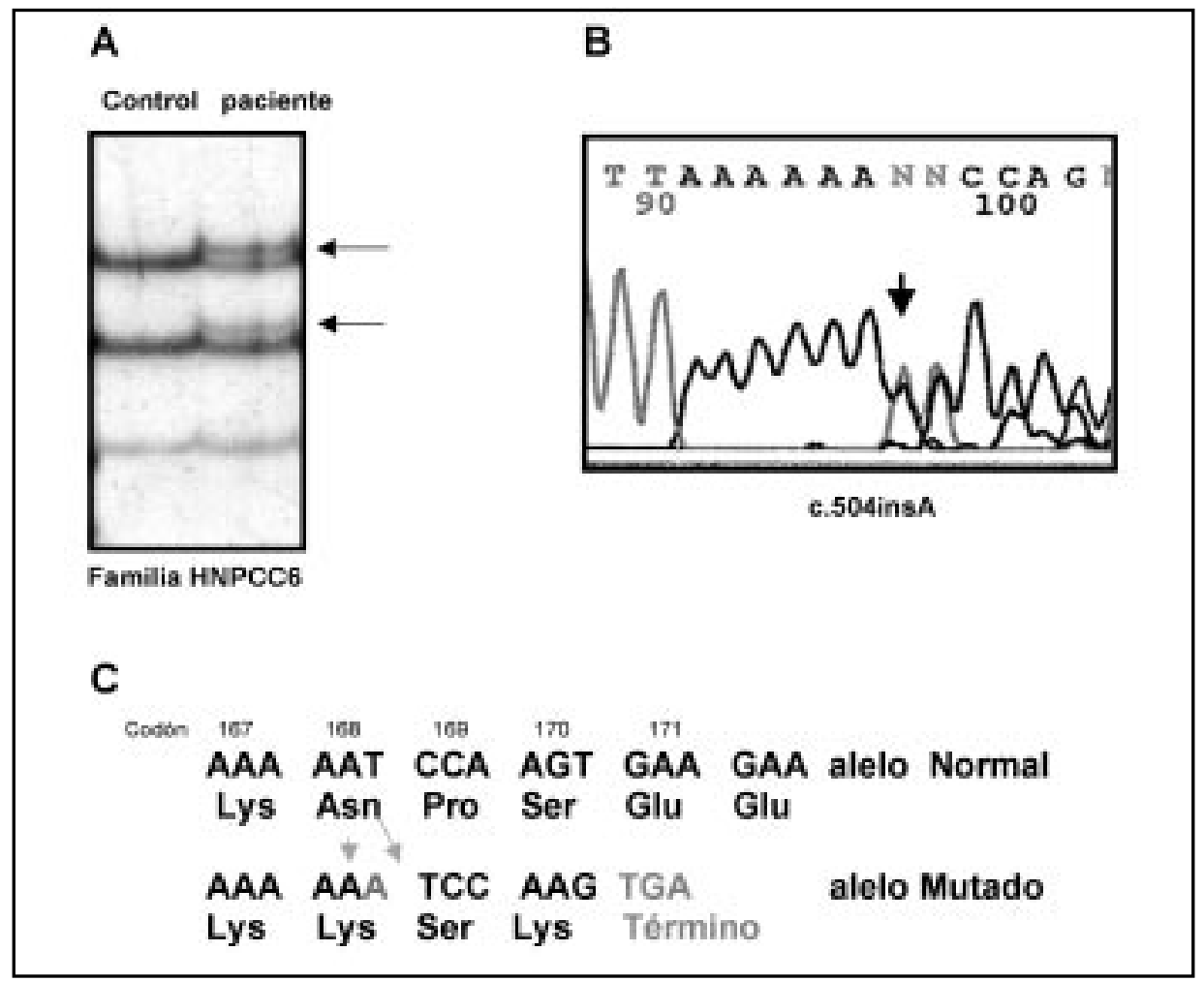

Figura 4. Análisis molecular del gen MLH1 en la familia HNPCC6. A: Análisis por SSCP de un fragmento del exón 6 del gen MLH1: se muestra una sección de la electroforesis en gel de MDE 0,5 X. Las flechas indican las bandas con migración electroforética diferente al control. B: Resultado de la secuencia de ADN: la flecha indica el inicio de secuencia alterada en uno de los alelos. C: Secuencias normal y mutada: se indica la lectura de las secuencias comespondientes a los dos alelos que presenta el paciente, indicando la inserción de una adenina en el nucleótido 504 del cADN. Bajo cada secuencia se indica el aminoácido comespondiente a cada codón, y sobre ésta la posición del codón en el mARN.

subsecuente necesidad de proctocolectomía ${ }^{27}$ y un comportamiento más agresivo de la enferme$\operatorname{dad}^{31,32}$, que la mayoría de los casos de PAF. En las familias estudiadas, se demuestra un fenotipo de la enfermedad agresivo y de aparición precoz, con un caso operado antes de los 10 años, otro a los 18, y dos familiares muertos por cáncer antes de los 40 años. Efectivamente, en el seguimiento de dos pacientes portadores de esta mutación y que han sido sometidos a una colectomía total se ha observado el desarrollo de múltiples pólipos rectales que no han respondido a la terapia farmacológica con Celecoxib ${ }^{33}$. Esto hace pensar que en un corto plazo será necesario extirpar el recto. En este sentido, un mejor conocimiento respecto a la asociación genotipo-fenotipo podría permitimos plantear en los familiares asintomáticos y portado- res de esta misma mutación un enfoque terapéutico distinto desde el inicio. Por todo lo anterior, concordamos con $\mathrm{Wu}$ y $\operatorname{cols}^{27}$ al afirmar que en individuos portadores de mutaciones en el codón 1309, el tamizaje endoscópico debe comenzar precozmente. En el caso inverso, es decir, pacientes que se presenten con poliposis en edades tempranas o de comportamiento agresivo, el estudio mutacional se debe iniciar en la región del exón 15 que contiene esta mutación.

Esta mutación también se ha descrito en familias donde aparece un caso de PAF sin antecedentes familiares, lo cual se denomina mutación de novo ${ }^{34}$. Como se observa en la Figura 1B, el paciente y su padre son los únicos que han presentado poliposis (ambos abuelos vivos y sin evidencia de enfermedad), sugiriendo que la mutación ocurrió por prime- 
ra vez en el padre. Este hecho concuerda con que la mutación ocurre en una región del gen llamada punto caliente»(hot spot), es decir, con alta probabilidad de sufrir mutaciones.

Una situación distinta es la que se observa en los pacientes HNPCC, ya que como su abreviación lo señala, este cáncer no se asocia al desarmollo de múltiples pólipos y, de este modo, se debe ser muy riguroso en la selección de los pacientes que se estudiarán. Desde el punto de vista costo-efectividad, debieran estudiarse los pacientes que reúnan los criterios Amsterdam I ya que en ellos la probabilidad de encontrar mutaciones puede llegar a $60 \%-70 \%{ }^{5}$. Tal cual como se puede observar en la Figura 3, nos encontramos con una familia en la cual, además del caso índice, tres familiares de primer grado han presentado cáncer de colon en dos generaciones sucesivas, uno de ellos antes de los 40 años y además en la anatomía patológica se ha descartado una poliposis.

Con respecto al tratamiento de los pacientes HNPCC, vemos que ambos fueron sometidos a una colectomía total con anastomosis ileorrectal, conducta fundamentada por el alto riesgo de desarrollar un tumor metacrónico $(35 \%$ a $45 \%)^{26,35}$. Sin embargo, esta operación no excluye el riesgo de desarrollar un cáncer metacrónico del

\section{REFERENCIAS}

1. Mortalidad por Causa Específica 2002. Departamento de Estadísticas e Información de Salud. Ministerio de Salud, Chile.

2. Winawer S, Fletcher R, Rex D, Bond J, Burt R, FERRUCCI J ET AL. Colorectal cancer screening and surveillance: Clinical guidelines and rationaleupdate based on new evidence. Gastroenterology 2003; 124: 544-60.

3. Church J, Simmang C. Practice parameters for the treatment of patients with dominantly inherited colorectal cancer (Familial Adenomatous Polyposis and Hereditary Nonpolyposis Colorectal Cancer). Dis Colon Rectum 2003; 46: 1001-12.

4. Rabelo R, Foulkes W, Gordon P, Wong N, Yuan ZQ, MacNamara E et al. Role of molecular diagnostic testing in familial adenomatous polyposis and hereditary nonpolyposis colorectal cancer families. Dis Colon Rectum 2001; 44: 437-46. recto cuya probabilidad es de $11 \%^{3}$, por lo que se justifica un seguimiento endoscópico de por vida.

La mutación c.504insA del gen MLH1 fue descrita en el año $2003^{36}$ por primera vez, en un paciente de un estudio de 59 familias HNPCC de la población norteamericana. Esta mutación produce el desplazamiento del marco de lectura del mARN con lo que se sintetiza una proteína truncada en el codón 171, que constituye cerca de $23 \%$ del tamaño de la proteína normal. No se describen en la literatura estudios funcionales de esta mutación. Sin embargo, el hecho de que la proteína se presente como un fragmento pequeño, que carece de los sitios de unión a las otras enzimas que participan en el complejo de reparación del ADN, lleva a afirmar que la proteína no sería funcional.

Este estudio es el primero, en el medio nacional, en identificar mutaciones en pacientes portadores de variantes hereditarias de cáncer colorrectal. La relevancia de estos resultados radica, tanto en la modificación de conductas terapéuticas en los pacientes que manifiestan la enfermedad (por la correlación genotipo-fenotipo), como en la detección de familiares asintomáticos portadores de la mutación, objetivo secundario de este proyecto.

5. Lynch H, De La Chapele A. Hereditary colorectal cancer. N Engl J Med 2003; 348: 919-32.

6. Strate L, SyngaL S. Hereditary colorectal cancer syndromes. Cancer Causes Control 2005; 16: 201-13.

7. Campbell W, Spence R, Parks T. Familial adenomatous polyposis. Br J Surg 1994; 81: 1722-3.

8. Jang Y, Steinhagen R, Heimann T. Colorectal cancer in familial adenomatous polyposis. Dis Colon Rectum 1997; 40: 312-6.

9. Kropilak M, Jagelman D, Fazio V, Lavery I, McGanNON E. Brain tumors in familial adenomatous polyposis. Dis Colon Rectum 1989; 32: 778-82.

10. Norton I, Gostout C. Management of periampullary adenoma. Dig Dis 1998; 16: 266-73.

11. Offerhaus G, Entius M, Giardielo F. Upper gastrointestinal polyps in familial adenomatous polyposis. Hepatogastroenterology 1999; 46: 667-9.

12. Soravia C, Berk T, McLeod RS, Cohen Z. Desmoid disease in patients with familial adenomatous polyposis. Dis Colon Rectum 2000; 43: 363-9. 
13. Chapman P, Church W, Burn J, Gunn A. Congenital hypertrophy of retinal pigment epithelium: a sign of familial adenomatous polyposis. BMJ 1989; 298: 353-4.

14. Groden J, Thliveris A, Samowitz W, Carlson M, Gelbert L, Albertsen H et al. Identification and characterization of the familial adenomatous polyposis coli gene. Cell 1991; 66: 589-600.

15. Aaltonen L, Salovaara R, Kristo P, Canzian F, Hemminki A, Peltomäki $\mathrm{P}$ et al. Incidence of hereditary nonpolyposis colorectal cancer and the feasibility of molecular screening for the disease. N Engl J Med 1998; 338: 1481-7.

16. Lynch H, Shaw M, Magnuson C, Larsen AL, Krush AJ. Hereditary factors in cancer. Study of two large midwestern kindreds. Arch Intern Med 1966; 117: 206-12.

17. FuLerton DA, López F, RAHMER A. Cáncer colorrectal hereditario no poliposo: tratamiento quirúrgico y análisis de genealogías. Rev Méd Chile 2004; 132: 539-47.

18. Soto G, López-Köstner F, Zárate A, Vuletin F, Rahmer A, León F et al. Poliposis adenomatosa familiar: alternativas terapéuticas y estudio de los familiares. Rev Méd Chile 2005; 133: 1043-50.

19. LAHIRI DK, NURNBERGER JI. A rapid non-enzimatic method for the preparation of HMW DNA from blood for RFLP studies. Nucleic Acids Res 1991; 19: 5444.

20. Miyoshi $Y$, Ando H, Nagase H, Nishisho I, HoRi A, MIKI Y ET AL. Germ-line mutations of the APC gene in 53 familial adenomatous poliposis patients. Proc Natl Acad Sci 1992; 89: 4452-6.

21. Kolodner R, Hall N, Lipford J, Kane M, Morrison P, FinAN P ET AL. Structure of the human MLH1 locus and analysis of a large hereditary nonpolyposis colorectal carcinoma kindred for MLH1 mutations. Cancer Res 1995; 55: 242-8.

22. Han HJ, Maruyama M, Baba S, Park JG, Nakamura Y. Genomic structure of human mismatch repair gene, hMLH1, and its mutation analysis in patients with hereditary non-polyposis colorectal cancer. Hum Mol Genet 1995; 4: 237-42.

23. Kolodner R, HaLl N, Lipford J, Kane M, Rao MS, MoRrISON P ET AL. Structure of the human MSH2 locus and analysis of two Muir-Torre kindreds for MSH2 mutations. Genomics 1994; 24: 516-26.

24. Heiskanen I, Luostarinen T, Järvinen J. Impact of screening examinations in familial adenomatous polyposis. Scand J Gastroenterol 2000; 35: 1284-7.

25. Järvinen $H$, Aarnio $M$, Mustonen $H$, Aktan-Collan K, Aaltonen L, Peltomäki P. Controlled 15-year trial on screening for colorrectal cancer in families with hereditary nonpolyposis colorectal cancer. Gastroenterology 2000; 118: 829-34.

26. De Vos Tot Nederveen Cappel W, Nagengast $F$, Griffioen G, Menko F, TaAl B, Kieibeuker J et al. Surveillance for hereditary nonpolyposis colorectal cancer. Dis Colon Rectum 2002; 45: 1588-94.

27. Wu JS, Pual P, McGannon EA, Сhurch JM. APC genotype, polyp number, and surgical options in familial adenomatous poliposis. Ann Surg 1998; 227: 57-62.

28. Caspari R, Friedl W, Mandl M, Mosiein G, Kadmon M, KNAPP M ET AL. Familial adenomatous poliposis: mutation at codon 1309 and early onset of cancer. Lancet 1994; 343: 629-32.

29. Bertario L, Russo A, Sala P, Varesco L, Giarola M, MoNDIN P ET AL. Multiple approach to the exploration of genotype-phenotype correlations in familial adenomatous polyposis. J Clin Oncol 2003; 21: 1698-707.

30. Friedl W, Caspari R, Sengteluer M, Uhlhass S, Lamberti C, JungCK M ET AL Can APC mutation analysis contribute to therapeutic decisions in familial adenomatous polyposis? Expenience from 680 FAP families. Gut 2001; 48: 515-21.

31. Ficari F, Cama A, Valanzano R, Curia MC, PalmiroTTA R, AсEто G et al. APC gene mutations and colorectal adenomatosis in familial adenomatous polyposis. Br J Cancer 2000; 82: 348-53.

32. Distante S, Nasioulas S, Somers GR, Cameron DJS, Young MA, ForReSt SM ET aL. Familial adenomatous polyposis in a 5 year old child: a clinical, pathological, and molecular genetic study. J Med Genet 1996; 33: 157-60.

33. Steinbach G, Lynch P, Phimps R, Walace M, Hawk E, Gordon $G$ et aL. The effect of Celecoxib, a cyclooxigenase-2 inhibitor, in familial adenomatous polyposis. N Engl J Med 2000; 342: 1946-52.

34. Aretz S, Uhlhass S, Caspari R, Mangold E, PagensteCHER C, Propping P ET al. Frequency and parental origin of de novo APC mutations in familial adenomatous poliposis. Eur J Hum Genet 2004; 12: 52-8.

35. LóPEZ F, ZÚÑIGA A, WistuBA I. Cáncer colorrectal hereditario no poliposo: bases genéticas del tratamiento quirúrgico. Rev Chil Cir 2002; 54: 107-13.

36. Wagner A, Barrows A, Wijnen J, Van Der Kuft H, FranKen P, VerkujJen P et aL. Molecular analysis of hereditary nonpolyposis colorectal cancer in the United States: High mutation detection rate among clinically selected families and characterization of an American Founder Genomic Deletion of the MSH2 Gene. Am J Hum Genet 2003; 72: 1088-100. 